\title{
AVALIAÇÃO DA EDUCAÇÃO BÁSICA EM ESCOLAS INDÍGENAS: O DIREITO A DIFERENÇA E A EDUCAÇÃO INTERCULTURAL EM UM CONTEXTO DE EXCLUSÃO SOCIAL
}

\author{
Maria Simone Jacomini Novak \\ Universidade Estadual do Paraná (UNESPAR), Curitiba, Paraná, Brasil \\ Rosângela CéLIA Faustino \\ Maria Christine Berdusco Menezes \\ Universidade Estadual de Maringá (UEM), Maringá, Paraná, Brasil
}

\begin{abstract}
Resumo: A Educação Escolar Indígena se consolidou no âmbito das reformas do Estado, nos anos de 1990, sob as bases da diferença, do bilinguismo e da especificidade, no momento de reorganização do sistema educacional, orientado pelos organismos e agências internacionais. Pela diversidade cultural e linguística dos povos indígenas no Brasil, pelas condições de extrema pobreza em que vivem, o tema da avaliação da aprendizagem ou da avaliação institucional é extremamente complexo, tendo em vista o histórico de exclusão e as políticas assimilacionistas. Este texto aborda a avaliação da educação básica indígena, analisando os limites da avaliação padronizada para um contexto de especificidade cultural e de exclusão social, destacando a necessidade de construção de novos parâmetros, desenhados e operados em conjunto com os povos indígenas.
\end{abstract}

Palavras-chave: Educação Escolar Indígena. Exclusão Social. Avaliação. Diversidade Cultural.

INTRODUÇÃO

O direito à diferença e a uma educação pautada na interculturalidade e em processos próprios de aprendizagem é uma conquista recente para os povos indígenas. $O$ Art. 14 da Declaração das Naçóes Unidas sobre os Direitos dos Povos Indígenas determina que "os povos indígenas têm o direito de estabelecer e controlar seus sistemas e instituições educativos, que ofereçam educação em seus próprios idiomas, em consonância com seus métodos culturais de ensino e de aprendizagem" (ONU, 2008, p.10). Esses princípios, bem como outras questóes relativas a direitos que destinam a essas populações políticas públicas, sejam elas na área de educação, sejam na área da proteção social, se ampliam no Brasil após a Constituição de 1988, que, seguindo as diretrizes internacionais, apontavam para programas de transferência de renda como forma de combate à pobreza e à vulnerabilidade das famílias de baixa renda. As políticas de prote 
ção social no Brasil iniciaram um processo que culminaria na criação de programas como o Programa Bolsa Família' e em uma política de assistência social baseada em direitos, que beneficia grupos como os indígenas.

Desde os anos 1960, no âmbito da política desenvolvimentista, organismos e agências internacionais vêm formulando políticas de atenção às minorias. $O$ artigo 27 do Pacto Internacional sobre Direitos Civis e Políticos da ONU, de 1966, determinou: "Naqueles Estados em que existem minorias étnicas, religiosas ou linguísticas, não será negado às pessoas pertencentes a tais minorias o direito de desfrutar a própria cultura, professar e praticar a própria religião e usar a própria língua".

A partir da década de 1980 , com o processo de reestruturação produtiva do sistema de mercado, nos moldes do neoliberalismo, o Banco Mundial, em renegociação com os países devedores, orientou reformas no aparelho do Estado. Conforme BRESSER PEREIRA (1995, p.13), elas se fizeram necessárias para que "o Estado reduzisse seu papel de executor ou prestador direto de serviços, mantendo-se, entretanto no papel de regulador e provedor destes, principalmente dos serviços sociais como educação e saúde [...]". Desenvolveram-se no Brasil programas de ajustes estruturais e reformulação das políticas educacionais, com a implementação da avaliação educacional em larga escala.

Em busca da regulação e controle da educação, foram várias as formas e modalidades de avaliação implantadas no Brasil, destacando-se o Sistema Nacional de Avaliação da Educação Básica (SAEB), o Exame Nacional de Ensino Médio (ENEM), o Programa Internacional de Avaliação dos Estudantes (PISA) e outros.

O Plano Decenal de Educação para Todos (BRASIL, 1993, p. 59), um dos primeiros documentos da reforma, trouxe articulações para a formulação de uma política de avaliação que envolveu a Secretaria de Educação Fundamental (SEF), o Instituto Nacional de Estudos e Pesquisas Educacionais (INEP), a Coordenação de Planejamento Setorial (CPS) e a Coordenação de Aperfeiçoamento de Pessoal de Nível Superior (CAPES), órgãos voltados à implementação do $\mathrm{SAEB}$, com a finalidade de aferir a aprendizagem dos alunos e o desempenho das escolas e prover informações para avaliação e revisão da formação de professores.

Segundo o documento, seus objetivos compreendem a pesquisa $e$ desenvolvimento de métodos e instrumentos de avaliação escolar, a implementação em universidades, centros de pesquisa e em núcleos ou centros regionais de estudos em avaliação, a formação e capacitação de recursos humanos para a área e a produção de pesquisa aplicada para subsidiar políticas públicas de qualidade educacional.

Em relação à diversidade e ao tratamento com as minorias, uma ampla mudança foi iniciada visando ao atendimento das orientações dos organismos internacionais (UNESCO, 1982), tendo entre seus objetivos a redução da pobreza via educação, sem, contudo, discutir sua lógica geradora. Além disso, podemos destacar a inadequação de modelos de avaliação padronizados para uma população que vive com suas particularidades culturais, mas cercada pela lógica do sistema de expropriação e acumulação capitalista, que a coloca em situação de pobreza econômica.

Neste texto, abordamos a limitação da avaliação da educação básica indígena, discutindo a política educacional atual e as informaçōes estatísticas sobre as realidades socioculturais e educacionais disponibilizadas pelo Instituto Nacional de Estudos e Pesqui 
sas Educacionais (INEP), que mostram que as populações indígenas vivem em um contexto de pobreza e exclusão dos bens desenvolvidos pelo capitalismo. Apontamos os limites da avaliação padronizada e a necessidade de se construir novos parâmetros, desenhados e operados em conjunto com os povos indígenas e suas realidades culturais e econômicas.

Iniciamos apresentando os direitos dos povos indígenas a partir de legislações internacionais e da proposição de parâmetros de educação intercultural e bilíngue, no contexto de utilização da educação como forma de aliviar a pobreza. Fazemos um breve histórico da implementação do sistema de avaliação brasileiro, inserido em um modelo de Estado que busca a regulação das políticas e ações, no âmbito das reformas com perspectivas de políticas focalizadas, desenhadas para o Brasil e toda América Latina a partir dos anos 1990, no qual a avaliação regula o financiamento da educação.

Discutimos a legislação para a Educação Escolar Indígena que referenda os direitos a currículos, propostas e práticas pedagógicas diferenciadas, alicerçadas nos princípios da interculturalidade e do bilinguismo, cujas bases não coadunam com programas de avaliaçóes padronizadas. $O$ direito à diferença exige que o estado busque novos parâmetros para a avaliação da educação intercultural bilíngue, de forma que sejam planejados e executados em conjunto com os povos indígenas, considerando suas culturas e aspectos socioeconômicos.

\section{EXCLUSÃO INDÍGENA E O DIREITO À DIFERENÇA}

Em meados da década de 1970, organismos e agências internacionais intensificaram a formulação de políticas de inclusão para populações indígenas por meio de projetos econômicos. O documento intitulado Aspectos estruturantes da pobreza entre os grupos da América Latina, publicado pela Comissão Econômica para a América Latina e o Caribe (CEPAL), apresentou e discutiu os elementos básicos da situação dessas populações, evidenciando que a questão indígena não poderia mais ser tratada de forma isolada, em decorrência da desvantagem em que as comunidades se encontravam e pelos impactos desintegradores que sofrem nos processos de desenvolvimento (DURSTON, 1979).

No período da reestruturação econômica, conduzida pelos organismos internacionais, as políticas afiançaram maior reconhecimento da diversidade cultural ao evidenciar que "la comunidad internacional considera que es su deber velar por la preservación y la defensa de la identidad cultural de cada pueblo. Todo ello invoca políticas culturales que protejan, estimulen y enriquezcan la identidad y el patrimonio cultural de cada Pueblo [...]" (UNESCO; CEPAL; OEA, 1979, p. 24).

Defendeu-se a necessidade de se estabelecer medidas enérgicas baseadas na participação, distribuição e mudanças legais, que propiciariam maior igualdade e reconhecimento cultural. Nesse bojo, as políticas sociais tomam contornos de assistencialismo, visando minimizar os efeitos oriundos das políticas neoliberais, devastadores para os pobres. O sistema capitalista cria um contingente de excluídos vivendo à margem da sociedade, dentre os quais os grupos minoritários, como os indígenas. Nesse contexto, são necessários mecanismos de inclusão para algumas dessas pessoas, o que ocorre através de uma série de políticas de atendimento de demandas dos 
grupos focais em que se escolhem os mais pobres entre os pobres, o que o Banco Mundial chama de "programas sociais bem focados" (FAUSTINO, 2006).

Desde o início dos anos 1990 e ao longo das duas últimas décadas o Banco Mundial tem atuado para aliviar a pobreza extrema, que pode desencadear conflitos sociais no interior do sistema. Por meio de documentos, como o Memorandum, de 1970, o órgão reafirma o propósito de investimentos em educação, reiterando, entretanto, a necessidade de avaliação do sistema educacional e do seu significado para o desenvolvimento econômico.

Além do reconhecimento da diversidade cultural e linguística, introduzido em todas as constituições latino-americanas no período, a Convenção 107 da OIT, de 1957 buscou assegurar às populações indígenas os direitos e possibilidades que a legislação nacional assegurava aos demais elementos da população, em condições de igualdade. $A$ Convenção 107 foi reestruturada e ampliada com a Convenção 169, de 1991, quando novos conceitos e ideias foram acrescidos, buscando-se a disseminaçâo e uma linguagem mais respeitosa à diversidade cultural.

Tendo participado da Conferência Mundial do México sobre Cultura e Desenvolvimento, realizada pela UNESCO no ano de 1982 (FAUSTINO, 2006), e de outros fóruns internacionais, onde os conceitos de autonomia e interculturalidade foram recomendados, o Brasil iniciou mudanças na política indigenista que culminaram no fim da tutela, no direito ao uso das línguas indígenas na escola, no reconhecimento dos processos próprios de aprendizagem e outras garantias expressas na Constituição Federal de 1988 e leis subsequentes. Em 1991, por força do Decreto Presidencial n²6, o Ministério da Educação (MEC) assumiu a responsabilidade pela Educação Escolar Indígena, passando a estabelecer novas diretrizes, cujas bases legais estão calcadas no bilinguismo, na interculturalidade, na especificidade e na diferença.

No mesmo período, no âmbito das reformas do aparelho de Estado (BRESSER PEREIRA, 1995), em atendimento às orientações do Banco Mundial e do Fundo Monetário Internacional (FMI) para a reestruturação econômica e política da região, iniciou-se a formulação de um modelo de avaliação escolar padronizado para regular o desempenho das escolas com avaliações escritas e em língua portuguesa, procedimentos que não coadunam com o reconhecimento da diversidade, a focalização nas populações indígenas e as brechas de ingresso (PSACHAROPOULOS; PATRINOS, 1994).

Ao serem divulgados os dados de avaliação do Sistema, como o Índice de Desenvolvimento da Educação Básica (IDEB), e o Exame Nacional do Ensino Médio (ENEM), nos deparamos com informações que, longe de evidenciar os processos próprios de aprendizagem que ocorrem nas escolas indígenas, estimulam, tão somente, o preconceito e a discriminação existente em relação às populações indígenas, sem considerar as condições de exclusão e pobreza ${ }^{2}$ a que estão submetidas.

Os resultados de dois indicadores divulgados em julho deste ano pelo MEC (Ministério da Educação) retrataram alguns problemas da educação escolar indígena no Brasil. No Enem 2009, a escola indígena Dom Pedro I, no Amazonas, foi a pior colocada do Brasil. No Ideb 2009, duas das 15 piores escolas do Estado de São Paulo 
estão neste tipo de comunidade, a Djekupe Amba Arandy e a Guarani Gwyra Pepo. CASADO; OLIVEIRA, 2010).

Conforme o Relatório Delors, “[...] os preconceitos raciais, fatores de violência e exclusão devem ser combatidos por uma informação mútua sobre história e valores das diferentes culturas" (DELORS, 2001, p.59). Os níveis de pobreza entre os indígenas se destacam quando comparados ao restante da população: "[...] si bien la pobreza es generalizada en América Latina y afecta a diferentes setores sociales, el analisis de la información existente demuestra que ésta afecta más la población indígena que la población no indígena". (BM, 1993, p.4).

A exclusão dos povos indígenas se expressa de diferentes maneiras: desde o violento processo de colonização à morosidade atual na demarcação das terras, os altos índices de pobreza (PSACHAROPOULOS; PATRINOS, 1994) a outras evidências, como o analfabetismo indígena, que é três vezes maior do que o índice nacional (IBGE, 2010). Apesar de figurarem muito pouco nas estatísticas e indicadores nacionais, informações do Instituto Nacional de Pesquisa Anísio Teixeira (INEP) revelaram que as crianças indígenas são alfabetizadas mais tarde, ficam retidas no $4^{\circ}$ ano do Ensino Fundamental até por volta dos 11 anos de idade e grande parte dos jovens indígenas está excluída do Ensino Médio (INEP, 2007).

Desde a publicação do Decreto 26/1991 identificam-se alguns avanços na Educação Escolar Indígena, como a construção de escolas na maior parte das aldeias (INEP, 2007), aumento do número de matrículas, contratação de professores indígenas, ações afirmativas para ingresso no ensino superior e criação de licenciaturas interculturais em várias regiões do Brasil (NOVAK, 2014). Destacam-se ainda a criação de programas de formação de mestres e doutores indígenas, como o Observatório da Educação Escolar Indígena (BRASIL, 2009), e a formação continuada de professores, por meio da Ação Saberes Indígenas na Escola (BRASIL, 2013).

Porém, as pesquisas documentais e de campo realizadas pelos projetos que deram origem a este texto ${ }^{3}$ evidenciam que a educação bilíngue intercultural pouco se concretiza. Muitas escolas ainda sofrem com a falta de infraestrutura básica (água, mobiliários, computadores, Internet), os currículos são padronizados, os materiais didáticos diferenciados e bilíngues são escassos, a formação superior dos professores indígenas é lenta e a implementação de programas de alfabetização bilíngue insuficiente (MENEZES, 2016).

Conforme as informações do Censo Demográfico do IBGE, em 2010 o Brasil tinha uma população de 896,9 mil indígenas, pertencentes a 305 etnias, falantes de 274 línguas. Além dos poucos dados educacionais disponibilizados, são escassas as informações linguísticas, socioculturais e etnográficas que auxiliem na compreensão da condição de ser indígena no Brasil hoje e de como a escola está contribuindo para o fortalecimento das culturas, línguas e identidades.

Para exemplificar a complexidade desse tipo de avaliação e a situação material em que vivem essas populações, podemos destacar o estado do Paraná, onde, segundo Mota (2009), indígenas vivem em pequenas terras, cercadas pelos grandes latifúndios que congregam os interesses do agronegócio e das monoculturas para a produção de commodities; assim, os recursos naturais são cada vez mais comprometidos devido às 
atividades do agronegócio do entorno, que poluem rios e comprometem a fauna e a flora; os solos das aldeias estão desgastados e as comunidades não têm recursos financeiros e tecnológicos para melhorá-los. Além disso, a destruição sistemática da natureza contribui para a disseminação de doenças e para a perda de práticas culturais importantes.

Observa-se situações de extrema pobreza, como é o caso dos Kaingang, pois há décadas eles têm como forma de subsistência principalmente as roças familiares e o artesanato:

Vivem do cultivo de suas terras com roças familiares e coletivas, da fabricação e comercialização do artesanato nas cidades vizinhas, do trabalho temporário nas fazendas das redondezas e complementam seu sustento com o que recebem dos programas sociais dos governos federal e estadual. (MOTA, 2009, p. 11).

Desta maneira, abordar a avaliação em escolas indígenas requer analisar as condiçóes estruturais e físicas desses estabelecimentos de ensino, a característica e formação de seus professores, a gestão, a participação da comunidade na elaboração do currículo e nos Projetos Pedagógicos e a implantação de programas bilíngues interculturais.

Ou seja, a avaliação da aprendizagem em escolas indígenas não pode ser negligenciada e nem desarticulada da avaliação institucional da realidade econômica a que essas populações estão submetidas. Embora sejam processos de natureza diferenciada e requeiram distintos instrumentos, as avaliações devem ser planejadas e desenvolvidas de maneira articulada, pois a falta de recursos materiais, atrelada à questão do bilinguismo, não podem ser desconsideradas.

\section{O ESTADO BRASILEIRO E A AVALIAÇÃO DA EDUCAÇÃO}

Como nos demais países da região, a atenção à diversidade cultural fez parte das reformas neoliberais conduzidas pelos organismos internacionais, tendo se iniciado também uma ampla reformulação da política educacional com uma nova perspectiva, a de inclusão social das minorias. Para o Banco Mundial,

A educação é a pedra angular do crescimento econômico e do desenvolvimento social e um dos principais meios para melhorar o bem-estar dos indivíduos. Ela aumenta a capacidade produtiva das sociedades e suas instituições políticas, econômicas e científicas e contribui para reduzir a pobreza, acrescentando o valor e a eficiência ao trabalho dos pobres e mitigando as consequências da pobreza [...]. (TORRES, 1998, p. 131).

Em consonância com esse princípio, a Declaração Mundial Sobre Educação para Todos (UNESCO, 1990) estabeleceu “a necessidade de definir, nos programas educacionais, os níveis desejáveis de aquisição de conhecimentos e implementar sistemas de avaliação de desempenho". As políticas públicas de regulação são indicadoras de compromissos governamentais com as organizações e organismos internacionais. 
Na América Latina, segundo Barreto (2001, p. 58), "praticamente todos os países implantaram alguma modalidade de sistema nacional de avaliação do rendimento escolar na última década". Ampliou-se a importância atribuída à avaliação em larga escala, visando, entre outros elementos, à quantificação da qualidade educacional.

No documento do Banco Mundial publicado em 2006, intitulado "Atualização das Estratégias do Setor de Educação: alcançando a educação para todos, ampliando nossa perspectiva e maximizando nossa efetividade - ESSU", verifica-se a perspectiva de que os investimentos em políticas sociais devem ser prioritariamente acompanhados de avaliação de seus resultados.

Segundo Freitas (2007), o Sistema Nacional de Avaliação da Educação Básica $(\mathrm{SAEB})^{4}$ foi criado como um mecanismo de monitoramento da qualidade da educação, por meio do qual provas são aplicadas bianualmente, objetivando avaliar o desempenho dos alunos do $5^{\circ}$ e do $9^{\circ}$ ano do Ensino Fundamental e da $3^{a}$ série do Ensino Médio. A avaliação contempla as disciplinas de Língua Portuguesa, com ênfase na leitura, e Matemática, com atividades baseadas na resolução de problemas. Além das provas, são aplicados questionários para levantar informaçóes sobre o contexto socioeconômico e cultural dos alunos, bem como sobre elementos de sua trajetória escolar.

O MEC utiliza os resultados das avaliações para estabelecer padrões de qualidade, orientação e definição dos investimentos. Com base nos resultados das avaliações em larga escala, são traçadas as linhas de prioridade. Em 2005 foi publicada a Portaria no. 931 do Ministério da Educação, instituindo o SAEB, composto por dois processos de avaliação: a Avaliação Nacional da Educação Básica (ANEB), e a Avaliação Nacional do Rendimento Escolar (ANRESC). Essa última recebe o nome de Prova Brasil (FREITAS, 2007).

Esse sistema de avaliação padronizada em larga escala contraria o que foi estabelecido em documentos da UNESCO, como o Relatório Delors, ao defender que "o respeito pela diversidade e pela especificidade dos indivíduos constitui, de fato, um princípio fundamental, que deve levar à proscrição de qualquer forma de ensino estandardizado" (DELORS, 2001, p.54). A UNESCO acrescenta que, "nesse contexto, a definição de uma educação adaptada aos diferentes grupos minoritários surge como uma prioridade. Tem como finalidade levar as diferentes minorias a tomar nas mãos o seu próprio destino [...]" (DELORS, 2001, p.56).

Uma das limitações dos modelos de avaliação padronizados recai sobre o currículo, que é diversificado e flexível, conforme a realidade das diferentes escolas existentes no Brasil, e cujos conhecimentos produzidos não têm relação com os conteúdos e procedimentos requeridos nas avaliações padronizadas. Dessa maneira, o sistema de avaliação implantado no Brasil através do SAEB é incompatível com a garantia da diversidade.

A educação voltada para o reconhecimento e respeito à diversidade requer currículos interculturais; propostas pedagógicas comunitárias; formação de professores com articulação entre teoria, práticas e saberes culturais que culminem na produção de materiais didáticos específicos e diferenciados; conteúdos e atividades didáticas capazes de responder às diferentes necessidades, interesses e capacidades dos alunos; reorganização da gestão e participação efetiva dos povos interessados no desenho e gestão destas políticas. Uma avaliação que vise um diagnóstico da realidade não pode prescindir de considerar essas especificidades. 


\section{A EDUCAÇÃO ESCOLAR INDÍGENA FRENTE À AVALIAÇÃO EM LARGA ESCALA}

A partir do início dos anos 1990, seguindo as orientações internacionais, o Brasil elaborou para a Educação Escolar Indígena um ordenamento jurídico pautado pelos princípios da interculturalidade, bilinguismo, especificidade, diferenciação e participação comunitária. Uma das primeiras ações foi a transferência da responsabilidade da coordenação das escolas indígenas da Fundação Nacional do Índio (FUNAI) para o Ministério da Educação.

Em 1996, a Lei de Diretrizes e Bases da Educação Nacional incorporou a Educação Escolar Indígena no sistema nacional de ensino, sendo sua especificidade tratada nos artigos 78 e 79, assegurando aos indígenas, por meio das escolas, o direito de reafirmarem suas culturas e identidades, bem como o acesso aos conhecimentos universais, inseridos em currículos próprios e materiais didáticos diferenciados.

No documento Diretrizes Curriculares Nacionais para a Educação Escolar Indígena (BRASIL, 1993, p. 19) definiu-se que a avaliação necessita estar diretamente ligada à questão dos conteúdos e metodologia, devendo ser entendida como diagnóstica e como um processo contínuo, vinculada à especificidade de cada escola indígena.

Em 1998, foi divulgado um dos mais importantes documentos da área, o Referencial Curricular Nacional para as Escolas Indígenas (RCNEI), que tem caráter formativo, contendo orientações e subsídios para a organização das propostas pedagógicas e programas das diversas disciplinas do currículo escolar, orientando também o processo de formação de professores indígenas (FAUSTINO, 2006).

Em 2009, foi realizada a I Conferência Nacional de Educação Escolar Indígena (I CONEEI), espaço importante de discussão dos povos indígenas sobre seus direitos e perspectivas educacionais. O documento da CONNEl registrou a importância da criação de Conselhos de Educação Escolar Indígena, bem como a necessidade de uma revisão das Diretrizes e Referenciais.

Revisadas, nas atuais Diretrizes Nacionais para a Educação Básica (BRASIL, 2013) a avaliação figura como um dos elementos que compóem o processo de ensino e aprendizagem, sendo uma estratégia didática que deve ter seus fundamentos e procedimentos definidos no projeto político-pedagógico, ser articulada à proposta curricular, às metodologias, ao modelo de planejamento e gestão, à formação inicial e continuada dos docentes e demais profissionais da educação, bem como ao regimento escolar. No que diz respeito à Educação Escolar Indígena, define-se que a avaliação deve estar associada aos processos de ensino e aprendizagem próprios, reportando-se à dimensão participativa e de protagonismo indígena da educação diferenciada.

Decorridas quase três décadas desde a Constituição Federal de 1988 e o Decreto n०. 26 de 1991, muitas escolas indígenas carecem de estrutura física adequada, currículos interculturais, projetos autônomos de ensino bilíngue que viabilizem suas garantias legais e avaliações dos processos de ensino e aprendizagem adequadas às diferentes realidades. A avaliação das escolas indígenas, conforme os direitos indígenas, deve ocorrer em consonância com a viabilização de seus sistemas próprios de ensino. 
A Resolução 03/99 do Conselho Nacional de Educação (CNE), que "Fixa Diretrizes Nacionais para o funcionamento das escolas indígenas", traz em seu artigo 70 a questão da avaliação articulada à formação de professores que atuam nas escolas indígenas para que se possa constituir uma educação diferenciada em diversos aspectos, entre eles o de avaliação:

Os cursos de formação de professores indígenas darão ênfase à constituição de competências referenciadas em conhecimentos, valores, habilidades, e atitudes, na elaboração, no desenvolvimento e na avaliação de currículos e programas próprios, na produção de material didático e na utilização de metodologias adequadas de ensino e pesquisa. (BRASIL, 1999).

A legislação nacional reafirma o direito dos povos indígenas à alfabetização das crianças em língua materna, bem como currículos, calendários e materiais didáticos específicos. A política de formação de professores indígenas considera, em suas orientações gerais, que deve se compor um sistema que vise também à avaliação escolar, bem como de suas propostas pedagógicas, o que incide também na avaliação da aprendizagem de crianças e jovens indígenas.

No documento Referenciais para a Formação de Professores Indígenas, ao se referir à proposta pedagógica da escola, atribui a ela importante papel também na avaliação das escolas:

É por meio delas que cada escola indígena pode definir seus fins educacionais e políticos, as decisões relativas às línguas com que os conhecimentos escolares se organizam e expressam, as áreas de estudo e os campos de interesse, os procedimentos de ensino, os tipos de aprendizagem considerados significativos, as formas de avaliação, o uso do tempo e do espaço. (BRASIL, 2002).

Conforme a Educação Escolar Indígena atual, a avaliação das escolas indígenas deve estar em consonância com os Projetos e Propostas Pedagógicas e o currículo intercultural bilíngue. De acordo com o Parecer do Conselho Nacional de Educação (CNE) $n^{\circ} \sigma$ de 2014, o Brasil deve formar, em nível da Educação Superior e, excepcionalmente, do Ensino Médio, docentes e gestores indígenas para atuar na Educação Escolar Indígena, com vistas ao exercício integrado da docência, da gestão e da pesquisa, assumida como princípio pedagógico; fundamentar e subsidiar a construção de currículos, metodologias e processos de avaliação e de gestão de acordo com os interesses de escolarização dos diferentes povos e comunidades indígenas.

Conforme estudos de Mileski e Novak (2012) e dos registros de campo, os Projetos Pedagógicos vêm sendo construídos de forma coletiva por professores e equipe pedagógica das escolas, no entanto da mesma forma que ocorre com as escolas não indígenas; nas escolas indígenas, o Projeto Político-Pedagógico (PPP) tem apenas cumprido com a formalidade exigida pelas secretarias de educação e demais órgãos da gestão escolar. Muito do que está proposto nos documentos não se efetiva, entre outras razões, pela questão econômica que afeta essas escolas.

Isso ocorre porque o PPP tem sido mais um documento técnico regulador do que um artefato cultural no qual as comunidades indígenas expressariam seus projetos educa 
cionais, que abrangeriam o espaço escolar e também a educação em suas múltiplas expressões culturais, uma vez que

as escolas indígenas possuem um envolvimento singular com a comunidade e com o contexto fora da sala de aula, que são desconsiderados pelos gestores públicos, que não compreendem essa situação. Assim, os gestores públicos questionam, muitas vezes, a atuação dos professores indígenas e a educação diferenciada e específica, chegando até mesmo a interferir, com políticas que desvalorizam a atuação das comunidades, por desconsiderar seu contexto. (ÂNGELO, 2005, p. 69).

Conforme a I CONEEI (BRASIL, 2009),

Os Territórios Etnoeducacionais supõem a criação de novos marcos legais e normativos para efetivar a autonomia pedagógica das escolas indígenas na formulação, desenvolvimento e avaliação dos projetos pedagógicos interculturais, contemplando todas as dimensões das práticas escolares, desde as propostas curriculares, a organização e gestão das escolas, a avaliação institucional e da aprendizagem, a definição dos calendários escolares e a regulamentação das escolas indígenas pelos órgãos competentes, enquanto escolas com normas e procedimentos jurídicos próprios.

Dessa forma, a avaliação das escolas indígenas, por meio do que foi estabelecido pelos próprios indígenas participantes da I CONEEl, carece de uma maior aproximação com as demandas das comunidades, que envolvem o investimento em infraestrutura física, formação de professores e gestores indígenas e a elaboração de uma avaliação que considere as especificidades desses povos, tão singulares frente à população em geral que participa do mesmo processo e instrumento de avaliação.

\section{CONSIDERAÇÕES FINAIS}

Diante da análise das políticas de reestruturação econômica implementadas a partir do final dos anos 1980 no âmbito da reforma do aparelho de Estado, que levaram a mudanças na política educacional com a deliberação de que é necessário o reconhecimento da diversidade cultural e linguística dos diferentes povos, a avaliação em larga escala, além de não dar a conhecer as diferentes realidades socioeducacionais indígenas, contribui, tão somente, para o aprofundamento do preconceito e da exclusão.

A aprendizagem escolar dos indígenas pauta-se pela especificidade, bilinguismo, interculturalidade e a participação indígena, requerendo, portanto, um sistema diferenciado de avaliação. Mais que isso, requer condições financeiras para a produção de material didático diferenciado e bilíngue, produzido junto com os indígenas, e sua adoção pelas escolas para o trabalho diário. Feito isso, as avaliações de diagnóstico da realidade devem considerar essa especificidade, lembrando que a elaboração das ferramentas de avaliação requer também a participação dos intelectuais indígenas. 
Há contradições entre as determinações da UNESCO e do Banco Mundial nos encaminhamentos educacionais que explicitam a predominância dos interesses econômicos e pouca viabilização dos interesses sociais pactuados com os povos indígenas. Desde a Constituição de 1988 e o Decreto Presidencial 26 de 1991, quase três décadas transcorreram sem que tenham sido desenvolvidos Projetos Pedagógicos e Currículos Interculturais que atendam a realidade sociolinguística e educacional das centenas de povos indígenas no Brasil.

A formulação de mecanismos específicos e diferenciados de avaliação contribuirá com a promoção da aprendizagem escolar, fortalecendo os processos de desenvolvimento social e econômico indígenas, respeitando as diferentes manifestações linguísticas e culturais e o exercício de seus direitos.

Artigo recebido em: 30/10/2018

Aprovado para publicação em: 18/12/2018

EVALUATION OF BASIC EDUCATION IN INDIGENOUS SCHOOLS: THE RIGHT TO DIFFERENCE AND INTERCULTURAL EDUCATION IN A CONTEXT OF SOCIAL EXCLUSION

ABSTRACT: The Indigeneous School Education was consolidated in the scope os state reforms during the 1990s, based on difference, bilingualism and specificity, in the reorganization of the system oriented by international agencies. Due to the cultural and linguistic diversity of indigenous peoples in Brazil, due to the extremely poor conditions in which they live, the theme of appraisal of learning or institutional evaluation is extremely complex given the history of exclusion and assimilationist policies. This paper addresses the evaluation of indigenous basic education by analyzing the limits of the standardized assessment for a context of culture specificity and social exclusion highlighting the need to construct new parameters, designed and operated together with indigenous peoples

KEYWORDS: Indigeneous School Education, Social Exclusion, Evaluation. Cultural Diversity.

\section{EVALUACIÓN DE LA EDUCACIÓN BÁSICA EN ESCUELAS INDÍGENAS: EL DERECHO A LA DIFERENCIA Y LA EDUCACIÓN INTERCULTURAL EN UN CONTEXTO DE EXCLUSIÓN SOCIAL}

RESUMEN: La Educación Escolar Indígena se consolidó en el marco de las reformas del Estado, en los años 1990, bajo las bases de la diferencia, del bilingüismo y de la especificidad, en el momento de reorganización del sistema orientado por los organismos y agencias internacionales. Por la diversidad cultural y lingüística de los pueblos indígenas en Brasil, por las condiciones de extrema pobreza en que viven, el tema de la evaluación del aprendizaje o la evaluación institucional es extremadamente complejo teniendo en cuenta el histórico de exclusión y las políticas asimilacionistas. Este texto aborda la evaluación de la educación básica indígena analizando los límites de la evaluación estandarizada para un contexto de especificidad cultural y de exclusión social destacando la necesidad de construir nuevos parámetros, diseñados y operados en conjunto con los pueblos indígenas.

PALABRAS CLAVE: Educación Escolar Indígena. Exclusión Social. Evaluación. Diversidad cultural. 
NOTAS

1) A importância de Programas como esse pode ser verificado no levantamento de dados e no estudo "O impacto do Programa Bolsa Família na melhoria do acesso à educação e aprendizagem em comunidades indígenas no Estado do Paraná", projeto realizado entre 2010 e 2011, financiado pelo Conselho Nacional de Desenvolvimento Científico e Tecnológico (CNPQ) junto com o Ministério do Desenvolvimento Social (MDS) e executado pelo Laboratório de Etnologia e Etno-história da Universidade Estadual de Maringá (LAEE/UEM). A pesquisa aponta que o programa tem proporcionado aos indígenas a aquisição de gêneros de primeira necessidade e maior ingresso e permanência das crianças na escola (FAUSTINO et al., 2011, p. 3).

2) Embora muito utilizado, entendemos que o termo pobreza é complexo. Segundo Azevedo e Burlandy (2010, p. 202), ele refere-se a “[...] um fenômeno complexo, composto por dimensões subjetivas, econômicas, sociológicas e políticas que variam conforme as especificidades locais, em razão das heterogeneidades sociais e culturais". Tratamos a pobreza aqui do ponto de vista econômico, atrelada a condições materiais mínimas para a manutenção da vida física, bem como a falta de acesso a bens e serviços como moradia, saúde, educação. Segundo os autores, o Banco Mundial vem “[...] difundindo uma ideia de pobreza para além da baixa renda, incluindo também baixos indicadores em educação, saúde, nutrição e outras áreas do desenvolvimento humano" (AZEVEDO; BURLANDY, 2010, p. 204). Antropologicamente, esse não é um termo adequado para designar as populações indígenas, principalmente considerando sua riqueza cultural. É muito recorrente nas falas dos indígenas a afirmação dessa riqueza. No geral, os indígenas não se referem a si como pobres, mas, sim, como sujeitos que têm muito a contribuir com a sociedade, enquanto grupos etnicamente ricos (NOVAK, 2014).

3) "A política dos organismos internacionais para a educação indígena no Brasil a partir do final dos anos de 1970: conferênciase documentos", da Unespar/Campus de Paranavaí e no Observatório da Educação Escolar Indígena da Universidade Estadual de Maringá.

4) Para um maior aprofundamento das discussões sobre o SAEB no contexto de implantação no Brasil do neoliberalismo e da implantação de um Estado regular, ver Freitas (2007) e Zanardino (2008).

\section{REFEREENCIAS}

ÂNGELO, Francisca Novantino Pinto de. A Inclusão das Escolas Indígenas no Sistema Oficial de Ensino em Mato Grosso. 2005. 100 f. Dissertação (Mestrado em Educação). Programa de Pós-Graduação em Educação. Universidade Federal do Mato Grosso, 2013. 
AZEVEDO, Darana Carvalho de; BURLANDY, Luciene. Política de combate à pobreza no Brasil, concepções e estratégias. Rev. katálysis [online]. 2010, vol.13, n.2, pp. 201-209.

BANCO MUNDIAL. Política operacional sobre povos indígenas e Estratégia para o desenvolvimento indígena. Banco interamericano de desenvolvimento. Washington, 2006.

BANCO MUNDIAL. Pueblos Indígenas y Desarrollo en América Latina, 1993. Disponível em: http://documents.worldbank.org/curated/en/685121468742892487/pdf/multipage.pdf. Acesso em 16 de set. 2013.

BARRETO. Elba Siqueira de Sá. A avaliação da Educação Básica entre dois Modelos. Educação \& Sociedade, ano XXII, n. 75, Ago. p.48-66, 2001.

BRASIL. Constituição (1988). Constituição da República Federativa do Brasil. Brasilia, DF. 1988.

BRASIL. Decreto Presidencial n. 26. Dispõe sobre a Educação Indígena no Brasil. Brasília, DF. 1991.

BRASIL. Plano Decenal de Educação para Todos 1993-2003. Brasília, 1993.

BRASIL. Resolução CEB nº 3, de 10 de Novembro de 1999. Fixa.

BRASIL. Diretrizes Nacionais para o funcionamento das escolas indígenas e dá outras providências. MEC, Brasília, 1999. Disponível em: http://portal.mec.gov.br/cne/arquivos/pdf/rceb03_99.pdf. Acesso em 16 de mar. de 2018.

BRASIL. Referenciais para a formação de professores indígenas. Secretaria de Educação Fundamental. Brasília: MEC; SEF, 2002.

BRASIL. Documento final da I Conferência de Educação Escolar Indígena. Luziânia-GO, 16 a 20/11/2009.

BRASIL. Portaria n 389, de 9 de maio de 2013. Cria o Programa de Bolsa Permanência e dá outras providências. DF, 2013.

BRESSER PEREIRA, L.A. Plano Diretor da reforma do Aparelho de Estado. Câmara da Reforma do Estado. Brasília, 1995. Disponível em: http://www.bresserpereira.org.br/documents/mare/planodiretor/planodiretor.pdf Acesso em: 10 Jul. 2016. 
CASADO, Leticia; OLIVEIRA, Camila de. Escolas indígenas são as piores nas avaliações do governo, 2010. Disponível em: http://noticias.r7.com/educacao/noticias/escolasindigenas-sao-as-piores-nas-avaliacoes-do-governo-20100725.html Acesso em 02 Ago. 2016.

DELORS, Jacques (Org.). Educação: um tesouro a descobrir. São Paulo: Cortez; Brasília: MEC/UNESCO, 2001.

DURSTON, John. Aspectos estruturales de la pobreza entre los grupos indigenas de America Latina. Instituo Latino Americano de Planificacion Economica Social. CEPAL, 1979.

FAUSTINO. Rosangela Celia. Política educacional nos anos de 1990: o multiculturalismo e a interculturalidade na educação escolar indígena.2006. 329 f. Tese (Doutorado) Programa de Pós-Graduação em Educação, Universidade Federal de Santa Catarina, Florianópolis, 2006.

FAUSTINO, Rosângela Célia; et.al. O Programa Bolsa Família e o acesso à educação escolar em comunidades indígenas Kaingang e Guarani no Paraná. Pesquisas de Avaliação MDS, v. 1, p. 1-18, 2011.

FREITAS, Dirce Nei Teixeira de. Avaliação e gestão democrática na regulação da educação básica brasileira: uma relação a avaliar. Educ. Soc. [online]. 2007, vol.28, n.99, pp.501-521.

IBGE. Instituto Brasileiro de Geografia e Estatística. Censo Demográfico, 2010. Disponível em: <www.ibge.gov.br >. Acesso em: 08 de nov. 2015.

INEP. Estatísticas sobre educação escolar indígena no Brasil. Brasília: Instituto Nacional de Estudos e Pesquisas Educacionais, 2007. 84 p.

KAHN, Mariana e AZEVEDO, Marta. O que está em jogo no desafio da escolarização indígena. In: Educação escolar indígena em Terra Brasilis, tempo de um novo descobrimento. Rio de Janeiro: IBASE, jul. 2004.

MILESKI, Keros Gustavo; NOVAK, Maria Simone Jacomini. A construção de Projeto Político-pedagógico em escolas indígenas Kaingang no Paraná: Primeiros apontamentos. Curitiba, Anais da IX ANPED SUl; 2012. Disponível em: $<$ http://www.ucs.br/etc/conferencias/index.php/anpedsul/9anpedsul/paper/viewFile/30 70/404>Acesso em 08 Ago. de 2016. 
MENEZES, Maria Christine Berdusco. A politica de educação escolar indígena e o processo de alfabetização em uma comunidade Kaingang no Paraná. 2016. 244 f. Tese (Doutorado) PPE, Universidade Estadual de Maringá, Maringá, 2016.

MOTA, Lúcio Tadeu. As Guerras dos Índios Kaingang: a história épica dos índios Kaingang no Paraná (1769 - 1934). 2. Ed. Maringá: EDUEM, 2009.

NOVAK, Maria Simone Jacomini. Os Organismos internacionais, a educação superior para indígenas nos anos de 1990 e a experiência do Paraná: estudo das ações da Universidade Estadual de Maringá. 2014. 342 f. Tese (Doutorado)-Programa de Pós-graduação em Educação, Universidade Estadual de Maringá, Maringá, 2014.

OIT. Organização Internacional do Trabalho. Convenção no 169 sobre povos indígenas e tribais e resolução referente à ação da OIT. Brasília: OIT, 1989.

ONU. Organização das Nações Unidas. Declaração das Naçóes Unidas sobre o Direitos dos Povos Indígenas, 2008. Disponível em:

https://www.un.org/esa/socdev/unpfii/documents/DRIPS_pt.pdf. Acesso em 17 de out. de 2017.

ONU. Pacto Internacional dos Direitos Econômicos, Sociais e Culturais, 1966. Disponível em: http://www.unfpa.org.br/Arquivos/pacto_internacional.pdf. Acesso em 17 de out. de 2008.

PSACHAROPOULOS, George; PATRINOS, Harry. Los indígenas y la pobreza en América Latina. In: Finanzas y Desarrollo. Fondo Monetario Internacional / Banco Internacional de Reconstrucción y Fomento. Washington, v. 31, n. 1, marzo 1994.

TORRES, R.M. Melhorar a qualidade da educação básica? As estratégias do Banco Mundial. In: DE TOMMASI, L; WARD M.J.; HADDAD, S. (Orgs). O Banco Mundial e as políticas educacionais. São Paulo: Cortez, 1998, p. 125-194.

UNESCO; CEPAL; OEA. Declaración de México. Aprovada por la Conferencia Regional de Ministros de Educación y de Ministros Encargados de la Planificación Económica de los Estados Miembros de América Latina y del Caribe. México: UNESCO, 1979.

UNESCO. Declaração Mundial sobre educação para todos. Brasília: Unicef, abr/1990, p.6983.

UNESCO. Mexico City Declaration on Cultural Policies. World Conference on Cultural Policies Mexico City, 26 July - 6 August 1982. Disponível em: http://portal.unesco.org/culture/en/files/12762/11295421661mexico_en.pdf/mexico_en .pdf. 
UNESCO. Declaração Universal sobre a Diversidade Cultural. 2002. Disponível em: $<$ http://www.dominiopublico.gov.br/download/texto/ue000115.pdfs $>$ Acesso em 10 Ago. 2016.

ZANARDINO, João Batista. Ontologia e avaliação da Educação Básica no Brasil (1990 2007). 2008. 208 f. Tese (Doutorado) - Programa de Pós-graduação em Educação, Universidade Federal de Santa Catarina, Florianópolis, 2008.

Maria Simone Jacomini Novak: Professora do Colegiado de Pedagogia da Universidade Estadual do Paraná (Unespar), Campus de Paranavaí - Doutora em Educação pela Universidade Estadual de Maringá (UEM).

E-mail:maria.novak@unespar.edu.br

RosÂngela Célia Faustino: Professora do Programa de Pós-graduação em Educação da Universidade Estadual de Maringá (UEM) - Doutora em Educação pela Universidade Federal de Santa Catarina (UFSC).

E-mail: rcfaustino@uem.br

Maria Christine Berdusco Menezes: Professora do Departamento de Teoria e Prática da Educação da Universidade Estadual de Maringá (UEM) - Doutora em Educação pela Universidade Estadual de Maringá.

E-mail: mcbmenezes@gmail.com

Este periódico utiliza a licença Creative Commons Attribution 3.0, para periódicos de acesso aberto (Open Archives Iniciative - OAI). 